\title{
Communities of Consumption and Made in Italy
}

\author{
ELEONORA DI MARIA* \& VLADI FINOTTO** \\ *Department of Economics, Università di Padova, Padova, Italy, \\ ${ }^{* *} T e D I S$ Center, Venice International University, Venice, Italy
}

\begin{abstract}
The interest towards the role of user communities in innovation has grown among scholars and practitioners. Research has explored the role of communities in high-tech and medium-tech industries with a focus on innovation in the functional dimension of products. Less attention has been devoted to user communities' contribution in industries such as fashion, where innovation is much more related to communication and aesthetics. This paper provides a preliminary set of concepts and working hypotheses regarding the contribution of communities to the non-functional dimension of product innovation in low-tech industries and to the relationship between user involvement in brand communities and their incentives to contribute to innovation both tangible and intangible. The paper discusses two case studies of Made in Italy enterprises that refer to communities for their innovation strategies.
\end{abstract}

KEY WORDS: Consumer communities, brand communities, innovation, Made in Italy

\section{Introduction}

The interest towards the role of user communities in innovation processes has grown among scholars and practitioners. The need to know more about the contribution of user communities in innovation processes stems from the increased visibility of these collective actors in several industries-from software to sporting equipment and many others. It has been widely shown that many consumers are far from being passive recipients of products and technical solutions developed by companies. They are rather active contributors in the process of new product development, providing valuable and useful technical knowledge, which can be effectively deployed in innovation processes (Nambisan, 2002; von Hippel and von Krogh, 2003). What determined the rise in the interest towards user intervention in innovation in the last 10 years is the scale of distributed innovation processes participated in

Correspondence Address: Eleonora Di Maria, Department of Economics, Università di Padova, Via del Santo 33, 35123 Padova, Italy. Email: eleonora.dimaria@unipd.it; eleonora.dimaria@univiu.org

1366-2716 Print/1469-8390 Online/08/020179-19 (C) 2008 Taylor \& Francis 
by users that information and communication technologies (ICT) have made possible (Hagel and Armstrong, 1998; von Hippel, 2005). Web and collaborative technologies allow individuals scattered in distant geographical areas to gather in specific online websites and collaboration areas and allow for the enactment of a potentially global pool of intelligence and capabilities (Sproull and Kiesler, 1991; Rheingold, 2002).

This paper discusses the contribution of consumer communities to the non-functional dimension of product innovation in low-tech industries, by focusing on Made in Italy small and medium-sized enterprises (SMEs). Our paper intends to offer an original point of view that links innovation literature with marketing and consumer research approaches, traditionally not adopted in the analysis, but fundamental to understand the role of user communities in innovation. From our perspective, innovation entails both the tangible and the intangible dimensions of product for customers' value creation and firm competitiveness. Innovation processes blend inputs from customers both in terms of technical knowledge rooted in the contexts of use and shared meanings and identities, exploited in firms' brand strategies (Muniz and O'Guinn, 2001).

Research in innovation studies has addressed the role of consumer communities especially in high-tech industries, in particular in the software and information and communication industries. Extant research and literature have focused diffusely on user contribution to functional and technical innovation (von Hippel, 1988). Instead, less attention has been devoted to user communities' contribution to innovation in industries such as fashion. Traditionally, the economic and management literature have defined these industries as "mature" or low-tech industries, by highlighting how innovation in fashion, for example, is much more related to communication and aesthetics than to functional features (i.e. Ravasi and Lojacono, 2005).

As many studies in this field have highlighted, innovation in traditional industries insists eminently on the intangible dimensions of products, rather than solely on their functionality (Krippendorf and Butter, 1984; Verganti, 2006). From this standpoint, the creation of experiences for customers is a fundamental part of firms' strategies in the mature industries to generate value (Schmitt and Simonson, 1997; Pine and Gilmore, 1999, 2007; Prahalad and Ramaswamy, 2003). Our perspective is that understanding and managing innovation in the present competitive scenario requires a stronger integration between innovation studies-traditionally focused on R\&D and technological innovation in product development-and the analyses offered by the marketing and customer behavior framework (i.e. Veryzer, 2005). Experiential marketing, relationship marketing approaches and studies on services stress the role of customers in value creation, where customers and the firm cocreate the firm's offerings (i.e. Normann, 2001; Lush et al., 2007).

In this approach, consumer communities can play an active role in such innovation processes. However, the nature of their contribution and the dynamics underlying it have been only partially described and formalized, as studies mainly focused on the functional side of products and gave minor emphasis on the communicative and aesthetic aspects of innovation. Literature on brand communities provides an initial set of categories and concepts (e.g. Muniz and O'Guinn, 2001) useful to fill this gap. Brand communities can sustain customers' involvement in the sense-making process-as a key component of innovation-which is activated by the firm but requires also customers' participation.

As successful cases show-that is, the example of Apple (The Economist, 2007) innovation is not always limited to technical and technological creativity (functional 
dimension of products), but it also or mainly covers artistic/aesthetic creativity (forms and meanings associated to products and brands). In our perspective innovation is the result of both these processes, where the role of communities of customers is related to support innovation from multiple directions and the role of consumption assumes a greater relevance on both sides (Bettiol and Micelli, 2005). As other studies pointed out (i.e. Sawhney and Prandelli, 2000), communities can be at the core of the innovation process, by shaping and being embedded in the locus of innovation. From our point of view, it is important to consider it also as a locus of experience where meanings and knowledge are developed and shared, among consumers and with companies (Prahalad and Ramaswamy, 2003).

The analysis presented in the paper refers to the Made in Italy economic system based on SMEs operating in mature industries. This specific focus allows us to address specifically consumer communities' contributions to the intangible and non-functional dimension of products, since a vast majority of Italian companies are focused on mature industries such as fashion. Despite many studies analyzing innovation within Italian industrial districts and firms' adoption of network technologies (e.g. Chiarvesio et al., 2004), very few discuss the role of communities of customers in innovation processes of Made in Italy and link those issues with brand strategy, which is relevant for firms' competitiveness in those industries (Corbellini and Saviolo, 2004).

The paper is organized as follows: first, we provide a review of the studies exploring the role of consumption in innovation processes. Second, we analyze the role of customers and user communities in non-functional innovation processes drawing from the marketing and consumer research literature. Third, the paper focuses on the chances for firms in exploiting communities of customers to sustain their competitive advantage through a broader innovation perspective. Next, according to a qualitative methodology, we discuss two selected exploratory case studies of SMEs specializing in Made in Italy industries that refer to communities as relevant elements of their innovation strategies.

\section{Online Consumer Communities and Innovation}

A large number of studies have shown that users of products and processes often develop fundamental innovations and that relevant learning about new product development happens outside the boundaries of the firm (Chesbrough, 2003; Franke and Shah, 2003; Jeppesen and Molin, 2003; Rosenberg, 1982; von Hippel, 2005). So far, the analyses of user innovation communities have successfully provided evidence regarding the motivations and rewards driving users in their efforts to improve products and processes and in revealing their knowledge freely (Harhoff et al., 2003). In addition, studies in the software industry and in the sporting equipment industry showed that innovation by users is more likely to take place in community settings rather than being a single innovator's solitary process (von Hippel, 2001; von Hippel and von Krogh, 2003; Jeppesen and Fredriksen, 2006).

Many innovations in the sporting equipment industry, for example, have been developed by users, rather than by manufacturers, as documented in Franke and Shah (2003). In the software industry, open source software such as Linux gained a prominent position as an alternative to proprietary software, thanks to the combined effect of user innovation and the active endorsement and contribution by hardware, software and consulting companies. In the electronic games industry, manufacturers are responsible for 
the creation of the main logical and functional architecture of a game and for the original storylines. After games are commercialized, further innovations in the game play are developed by passionate users, who contribute lines of code, graphics and modeling to the original products improving them and making them more appropriate to peculiar patterns of use and playing experiences (Jeppesen and Molin, 2003).

As stated in von Hippel (1988), the incentives to innovate are different for manufacturers and users. Manufacturers expect to benefit from a given innovation by selling it. On the one hand, this means that what drives the design of a new product by manufacturers is the forecast of a large demand for that product. On the other hand, innovations are likely to be developed by users if they are to benefit from their use (Franke and Shah, 2003). While not all users play such a part in the innovation process, research on the sources of innovation identified a particular type of user able to identify specific and sophisticated needs and to elaborate innovative responses: lead users (von Hippel, 1988, 2005; Morrison et al., 2004). As defined in von Hippel (1988), they are those users that have needs that anticipate general demand in the marketplace and that expect to obtain high benefit from a solution to their needs. The shift of the locus of innovation towards users has been explained as a consequence of information stickiness and its embeddedness in specific contexts of use (von Hippel, 1994). It has also been noted that attributes of the information holder and of his context play a crucial role: users often use languages that are extremely different from those used by manufacturers. Where manufacturers think in terms of processes, technologies and features, users think in terms of performance, practices and desires (Micelli, 2000).

Given the ability of lead users to develop new product concepts, features and prototypes, it is possible for manufacturers to shift part of the innovation process to them. In the software industry, for example, empowerment of customers led a number of software development companies to rely on the competences and skills of users in order to customize their products, responding thus to the needs of customization without having to bear the cost of doing it directly and the risk of not finding adequate markets (Franke and von Hippel, 2003; Jeppesen and Molin, 2003). Sophisticated users needing to adapt a particular application to their local needs can do it through software development kits.

User toolkits for innovation and customization (Franke and Piller, 2004; von Hippel, 2005) have become a major feature in the software as well as in other industries: they allow manufacturers not only to shift part of the burden for customization and innovation to users, but also to exploit commercially user-made innovations if they prove to be successful through user-to-user diffusion.

\section{User Communities in Marketing and Consumer Studies: Emerging Perspectives}

A second stream of literature focused on consumer communities does not have directly an interest in product innovation processes, but rather it analyzes how communities of consumers are active contributors to the construction of social identities, relational patterns, use contexts within which products are located and within which they are attributed with meaning (Cova, 1997; Hagel and Armstrong, 1998; Kozinets, 1999). Brands in particular have been at the center of the analyses of these works. Much of this literature has focused on the social nature of brands as the result of processes in which companies create 
complex systems of meanings drawing from particular cultures of consumption (e.g. Cova, 1997).

The creation of meanings and identities qualifying brands does not happen in a social void. Communities of customers represent an important actor in the creation and development of part of brands' values and communicative potential. The process is iterative. On the one hand, brands draw from cultures and subcultures of consumption (Schouten and McAlexander, 1995; Muniz and O'Guinn, 2001). On the other hand, consumers enact these meanings and identities in their everyday consumption and social practices, enriching and sometimes innovating their structure and re-defining the contents of brands. The appropriation of brands and products as signs by consumers aims at communicating their identities and values to other consumers in their everyday life.

These identities and the cultures associated with them are not the result of a singular and individual signification process, but are closely connected to the interaction within groups (Jenkins, 2006). Cova (1997) finds several occurrences of this type of bottom-up identity-building processes: the ravers culture in the UK during the 1990s, the skater culture in France. Being affiliated with these groups means adopting the communication and expressive instruments and semantics created by the group and at the same time contributing to their transformation and evolution through the negotiation of new meanings and new stimuli coming from the experiences consumers have. Cova, drawing from the sociological work of Maffesoli (1992), defines these collective sense-making actors as tribes, while many works in the consumer research field and in the marketing field define them as "communities". Within this framework products and brands perform a connecting function, linking consumers and enabling social relations based on distinctive consumption practices. This linking function is a crucial driver of value for customers in many markets for consumer goods, representing a fundamental share of the overall value perceived together with the functional content of goods and services.

\subsection{Brand Communities and Collective Sense-making in Consumption as a Form of Innovation}

Research on the communicative nature of brands evolved from the analysis of brands as shortcuts for product identification towards the analysis of brands as constructs linking consumers and companies. As stated earlier branding practices are not based on a monologue metaphor (Aaker and Joachimsthaler, 2000), which means they are not the result of a mono-directional communication and signification act by marketers. Designing the communicative arsenal of a brand with pre-defined values and meanings and distributing it to the market through traditional and new media seems a strategy destined to fail. The reason is that being used by consumers as signs for self-expression, brands and products have to reflect particular views of the world and lifestyles, which are pre-existent in consumption contexts and cultures. Works by Belk (1988) and Ahuvia (2005) clearly show that the relationship between consumers and brands-or objects-is determined by the inherent content of the brand itself: as long as it synthesizes the cultures and the identities of specific groups of consumers, they gain in perceived authenticity and become "loved objects". This can happen, though, only if brands reflect the results of sense-making processes taking place in the relational contexts within which consumers are inserted 
(Morling and Strannegard, 2004; Roberts, 2004). Rather than being pre-determined and immutable intangible artifacts, brands are narratives that include and continuously reinterpret the transformation that takes place in the consumer arena.

Thus, in many industries, consumers are actually active contributors to the brand: they are responsible for sense-making and identity building through social relationships and shared practices and interests. Is this process good for companies and partly controllable? The literature on consumer communities and particularly brand communities represents a first important step towards the understanding of these dynamics. Schouten and McAlexander (1995) have pointed out the potential impacts that subcultures of consumption can have on marketing practices and strategies. Hard-core members of a specific subculture gain a specific status of opinion leader and often contribute to create subcultural styles of consumption that can be shared and imitated by other consumers and can be detached from those designed by companies.

Their article conducts an in-depth analysis of a particular subculture, that of the "new bikers" who use Harley Davidson motorcycles. The involvement of consumers in the activities and in the life of the subculture generated what the authors call "grassroots R\&D": the more involved and technically savvy consumers in the subculture designed and built custom motorcycles which then the company refined and commercialized, such as the chopper and many more. The subculture started also to design and produce their own lines of clothing and aesthetic instruments of expression, giving further marketing ideas and instruments to the company. The user community becomes an active player in the innovation process, partly because of its inputs in terms of product features and partly because it is able to nurture discussion about the products that generate shared meanings (the symbolic dimension of product).

Muniz and O'Guinn (2001) have highlighted the active role played by brand communities, composed by individuals sharing a preference for a specific brand or product (see also Bagozzi and Dholakia, 2006). Passionate consumers of specific brands display an active role in interpreting and re-defining the meanings associated with brands and products, inserting them in a complex context composed by identities, values and other products which are socially negotiated. This active interpretive function of brand communities is responsible for the definition of the intangible value of products and brands and represents a strategic lever for companies willing to incorporate the outcomes of these processes in their offer. Although not specifically addressing the topic of innovation in consolidated terms, literature in consumer studies and marketing contributes to enlarge the definition of innovation itself, highlighting how the non-functional dimension of productsthe values and identities associated to brands and goods, the communicative and aesthetic content-constitutes a relevant share of products' value in consumer goods. As noted by Ravasi and Lojacono (2005):

Even companies that used to compete primarily on price or technological performance are increasingly facing the need to develop products that are not just efficient or reliable, but also responsive to emerging lifestyles and cultural values. (Ravasi and Lojacono, 2005: 52)

In addition, this stream of literature highlights the active role users play in contributing to the definition and the assessment of these elements. 


\section{Communities and Firms: Innovation Based on Use, Participation and Experience}

The contributions of consumer communities to the creation of value, based on the two streams of literature reviewed earlier, can be considered twofold: (i) user communities contribute to the creation of novel technical solutions and functional improvements of products of choice capitalizing their contextual knowledge and their consumption practices; (ii) user communities provide brands and products with part of the symbolic and communicative elements which are responsible for product value.

The issue at stake is not only a theoretical categorization of the different contributions of consumer communities to innovation processes, but rather the nature of the innovation process itself and the value of its outcome. As shown in a growing body of literature in innovation studies, design studies and marketing, innovation is a multidimensional phenomenon, and consumers' perception of the value of a new product depends on two different dimensions: the performance and technical dimension of a product, and its experiential and emotional content, which is embodied in its aesthetics, its style and the values and identities attached to its brands (Krippendorf and Butter, 1984; Pine and Gilmore, 1999). In this perspective, the contributions of marketing and design research are of an extraordinary importance to understand the role of communities of customers in the innovation process.

Today's consumers are increasingly facing a constant flow of innovative functions and features in many of the products they use. Moreover, in many consumer markets alternative products present many similarities under the standpoint of manufacturing excellence and technological content. Based on this evidence, it has been observed that manufacturing activities and manufacturing excellence are not the only determinants of the value perceived by customers (Porter, 1985; Rullani, 2004; Nussbaum et al., 2005).

On the contrary, scholars stated that the determinants at the basis of customers' perceived value resides increasingly, even though not exclusively, in intangible attributes, whose nature has been addressed through several concepts: aesthetics, communication and signification (Hirschman and Holbrook, 1982), luxury (Silverstein and Fiske, 2003), style (Postrel, 2004) and the like. The intangible content of products is said to be the fundamental determinant of consumers' willingness to pay premium prices for products they use, while the lack thereof is responsible for the trading down of goods and services (Silverstein and Fiske, 2003). Silverstein and Fiske note how a general trend is becoming visible in contemporary advanced societies: consumers are willing to pay significant premium prices for goods and services that are emotionally important for them.

These emerging trends do not imply that the inherent quality of products (intended as the outcome of sophisticated manufacturing skills and processes) or their technological and functional content do not play a part in the determination of value. They just re-allocate the relative contribution of tangible and intangible content in the generation of value.

The explanation often brought to these dynamics is that manufacturing capabilities and expertise are becoming commoditized, especially in low-tech industries. Consumers thus perceive that many if not all companies competing for their attention are equivalent in terms of manufacturing capabilities and quality is taken as granted and as the minimum common denominator of all the alternative offerings entering their decision processes (Pine and Gilmore, 2007). In this sense, investing in brands becomes a key strategy for firms to support competitiveness through a wider approach to innovation. As far as technology and 
innovation are concerned, the marginal importance of technological advancements in markets for consumer goods in generating value for the customer has decreased as a result of the continuous introduction of new products and new features in existing products.

This evidence seems to suggest the need for a re-definition of the concepts and practices of product innovation. Rather than focusing on technologies and continuous technological improvements, firms must gather information from consumers in order to understand their expectations and their inner and often tacit needs (Leonard and Rayport, 2000) and, most of all, they must work on the framing of technological developments and of product re-definitions within a complex discourse matching the requests for meaning and expression coming from consumers (Kotro and Pantzar, 2002). Aesthetic and intangible attributes of products trigger processes of identification which ease consumers' decisionmaking processes and which attribute products with meanings and transform them in expression instruments, beyond their functional features and quality.

These trends interest particularly mature and low-tech industries, such as fashion, since their products, which have reached a technological plateau, are increasingly being differentiated through intangible elements. Innovating means most of all qualifying products through aesthetics and designing complex cultural and communication activities and strategies centered on evocative and emotionally rich brands. Recently, analogous dynamics are also interesting markets for high-tech or medium-tech consumer products, such as computers, digital personal devices (music and movie players), mobile phones, cars and many more (Nussbaum et al., 2005).

Hence, firms should develop explicit processes to connect to lead users and communities of customers as part of their innovation strategies. As far as the nature of the relationship between companies and brand communities is concerned, it can be the result of at least two different strategies. On the one hand, companies can foster the growth of branded communities, which means of groups of people specifically gathered in branded environments-be they the company's website or sponsored events. On the other hand, companies can choose to relate to existing communities that share interests for specific consumption practices, characterized by a strong collective identity and by the mobilization of participants on the basis of these common elements. These communities are not directly connected with one specific brand, but rather consider some brands as being part of their culture and important elements in the definition of their identity. Such user communities gather in specific websites and online environments as well as in offline events, which can be sponsored but which are managed and run by members of the community rather than by personnel within the company. Monitoring, interacting and relating to these communities, even though not on an exclusive basis and within proprietary environments, can be strategic for companies to legitimize their brands and capture valuable suggestions and insights related to potential evolutions of their offerings, and of the specific demand they are addressing (Hagel and Armstrong, 1998; Rémy and Kopel, 2002).

\section{User Communities and Made in Italy: Case Studies}

The previous considerations regarding the nature of the contribution of consumer communities to product innovation and, more generally, to the creation of value, lead to the question how companies can start and consolidate relationships with these collective actors and how they can leverage these contributions in their business practices and 
innovation processes. In order to provide preliminary evidence that could stimulate further studies, two cases were selected within the so-called Made in Italy companies, which is the definition given to typical Italian SMEs located in industrial districts operating in low-tech or medium-tech industries. The two case studies analyzed in the following pages represent the preliminary result of a series of observations which have been undertaken in several Made in Italy companies. The case studies presented are exploratory in their objectives (Yin, 1994) and were developed in order to shed light on emerging processes of community involvement in innovation in industries such as fashion and sporting equipment. Rather than providing evidence regarding causal relationships, these cases are meant to provide an illustration of the types of conceptual proposals made in the previous parts of the paper (Siggelkow, 2007), and to stimulate further refinements.

These case studies were selected among a series of analyses of community involvement by Italian companies in traditional Made in Italy industries. Case studies were constructed through several interviews with R\&D managers and marketing managers in the interested companies (Di Maria and Micelli, 2007) and through the observation of the companies' online and offline communities—related activity. The selected case studies aim at providing a preliminary analysis of some relevant experiences and a first set of evidence to be developed in further and more structured research efforts.

\subsection{Innovation in Made in Italy}

Italian production has received great attention over the past decades, due to its strong combination of quality, variety and convenience. Italy's share of "G7" exports is about 66 percent in footwear, 55 percent in leather, 54 percent in gold jewelry and 37 percent in furniture (source: UNCTAD). Italy has shown extraordinary levels of export capacity over the years, counterbalanced by strong embeddedness of firms and manufacturing processes in local areas-the industrial districts (Pyke et al., 1990).

Many of the studies on industrial districts link the competitive force of such a form of local manufacturing organization to its internal cohesion (e.g. Pyke et al., 1990). The focus on manufacturing activities stresses the relevance of production processes and related skills and competencies rooted in the local context as the drivers for the competitiveness of the district firms (Becattini and Rullani, 1996). Industrial districts were able to develop profitable innovative processes, strictly related to their industry specialization and their peculiarity (Lazerson and Lorenzoni, 1999). By different degrees of opening of their core processes, firms share manufacturing activities (components etc.) with partners in a collaborative environment, which stimulate reciprocal learning and product improvements.

Italian industrial districts and local supply chains have represented for a long time one of the main strengths of the national industrial systems. Geographical, cultural and linguistic contiguity facilitated the birth and growth of inter-firm networks sustained by trust which allowed for the fragmentation of production cycles, for a great degree of specialization in single phases of production processes and for high flexibility and adaptation by SMEs (Corò and Grandinetti, 1999). These geographically bound supply chain structures made firms in industrial districts able to adapt rapidly to the different requests of changing consumers and to provide the adequate degree of variety in products increasingly demanded by heterogeneous consumers. Adaptation to changing tastes of consumers was granted by the geographical contiguity to advanced customers: in industries such as fashion, furniture, 
jewelry, the Italian market represented for a long time the most advanced frontier of innovation in tastes and in elegance. Italian consumers, thus, anticipated the needs and demands of consumers around the world. Capitalizing on consumers' knowledge was relatively easy, given the "captive" nature of consumers themselves: they were geographically close to local firms and shared widespread and consolidated product cultures (Becattini, 1991).

The situation has dramatically changed during the last years, and globalization brought the emergence of several hotbeds for innovation in consumption practices and trends. Even though classical Made in Italy products are appreciated by a large number of consumers worldwide, new trends and tastes in fashion, furniture and other low-tech industries are being created by consumers and companies in several areas. Metropolitan areas in the USA are responsible for many of the most visible and successful casual and informal trends in clothing-for example, streetwear-China and the Far East in general are the sources of innovative trends and styles in both clothing and furniture. In other words, innovative consumers and hotbeds for innovation in tastes and cultures of consumption are multiplying and companies willing to compete in markets for fashion and home product items are called to interact with these consumers and with their communities to gather innovative ideas and knowledge, intercept new trends, create a strong association between their brands and the prevailing identities, lifestyles and cultures.

Italian small and medium companies are challenged by this strategic change: they need to re-define their approach to consumer communities and sophisticated customers, which are not geographically close nor share their same cultures, languages and social backgrounds. While the absorption of consumer knowledge was traditionally eminently tacit for Italian SMEs, today it needs to rely on explicit practices and on a strategic intent. This new approach means developing strong customer intimacy through innovative channels, the promotion of experience and interactive communication, which require a transformation in the firm's organizational competences to compete. An important instrument to develop and sustain relationships with sophisticated consumers is represented by the Internet, intended as a set of technologies, which allows companies to enter in constant and continuing relationships with consumer communities on a global scale.

On the one hand, the main leading firms' strategies carried out within industrial districts consider the introduction of complex innovation as an important element of a firm's distinctiveness (Belussi et al., 2003). On the other hand, however, a completely different approach has to be developed when promoting innovation based on the involvement of customers and user communities, through social dynamics and shared sense-making. Following the Italian experience in the field of design and craft production, SMEs are redefining their capabilities in managing manufacturing processes and enhancing their relational capabilities in the marketing domain. Information and communication technology plays a crucial role in the activation and consolidation of relationships with geographically dispersed consumers (Micelli, 2000).

In the following paragraphs, we will analyze two case studies of Italian SMEs which have started to re-define their approach to markets through stable relationships with consumer communities, both online and offline, in order to identify the strategic contribution of communities to competitiveness and innovation in Made in Italy. The two case studies were selected according to the following criteria. Both the companies can be defined as typical Italian SMEs for size (less than 250 employees), industrial specialization (fashion is a 
key specialization of Made in Italy) and localization in or close to industrial districts (sport system district and clothing district). A second motivation for the selection is their positive economic performances. These companies have obtained positive economic performances while the average performance of competing companies located in the same areas and operating in the same industry has been at least stable if not decreasing in the last $4-5$ years as the result of increased global competition.

\subsection{DSL: Consumer Communities and Urban Cultures in the Fashion Industry}

55DSL is a company located in the area of Vicenza (Veneto region, northeast of Italy), home for many companies specialized in the production of clothing and fashion items. The company belongs to Diesel Group, a leading brand in the fashion industry. 55DSL became financially autonomous in 2005 and since then its turnover has grown from 1 million to more than 30 million euros worldwide. 55DSL was started as an experimental line oriented towards the street culture and the emerging fashion trends among young consumers influenced by the culture of skateboarding and extreme sports, later addressing also other cultures of consumption, in particular those of gamers and several music-related subcultures.

The styles and design of 55DSL products are directly influenced by the fashion trends going on in the action sports communities, and the company has sponsored many professional riders such as Tony Hawk, Joel Tudor and Steve Berra. The original inspiration coming from action sports has been then mixed with prevailing trends in urban and street culture-being the two very close, especially in the case of skateboarding clothes and urban clothes. The up-to-date design and styles associated with the company's products and brands is made possible by the continuous activity of trend scouting in several major cities which are the cradles of the most innovative trends in urban cultures around the world and that represent the focal points from which new styles and trends are diffused on international markets.

The design approach of the company recognizes the importance of the "Do it yourself" attitude prevailing today in the younger segments of fashion markets. Sophisticated consumers in the younger segments of the fashion market-aged 15-25-act like bricoleurs and integrate different clothing items and different styles in original and very personal ways of dressing and combining clothes. Maintaining a close relationship with young urban consumers is not fundamental only in marketing trends but increasingly useful also in order to adopt novel aesthetic and stylistic solutions into product innovation. Those solutions are developed by consumers which adapt and re-interpret existing styles and clothing lines, colors and designs as a means for self-expression and personalization.

What is generally defined as urban culture is the result of the influence of different subcultures and elements of popular culture: action sports and their aesthetics, urban fashion trends, videogames, musical subcultures. All these elements are continuously integrated in original and continuously evolving sets of identities, values and attitudes by individuals-consumers. The result of this mix is a valuable starting point for companies specialized in the production of fashion items and accessories. Interacting with these cultures is fundamental both for the strong association of a brand to prominent cultures in younger generations and for the identification of ongoing trends and potential evolutions. 
55DSL in particular focused on the importance of building a bridge with communities of gamers and with communities of young music fans.

55DSL approach to online communities. Although in its early stages, the company has started to develop a strategy based on the commitment and the interaction with online and offline consumer communities since, as its management states, this could lead to capitalization on useful sources of new ideas and styles. The company website has a blog within which subscribed users can contribute with original content, ideas, suggestions and multimedia content. In the company's own words (55DSL website, see Figure 1), the website is a "user-driven non-hierarchical social bookmarking" tool through which users decide the contents that will appear on the company home page and through which they will vote and comment on the most interesting contributions. All the messages and comments of the company are categorized by users in several areas, such as arts, fashion, culture, web picks and the like.

Every week users post more than 50 messages and discussion topics and contribute with pictures and multimedia items. The idea of the whole project is, on the one hand, to make the website a primary source of useful information and interactions for young urban consumers and, on the other hand, of the dynamics and evolution undergoing in the cultures and subcultures targeted by the company.

In 2006 the company developed a partnership with EA Sports, one of the major videogame publishers in the world, in order to sponsor with its clothes the major characters of the game Need For Speed Carbon. 55DSL's website had a dedicated section to this partnership within which, besides presenting marketing material for both the game and the clothing lines, registered users can take part in online competitions on games developed purposely for the community. Every week a contest was organized and each winner was

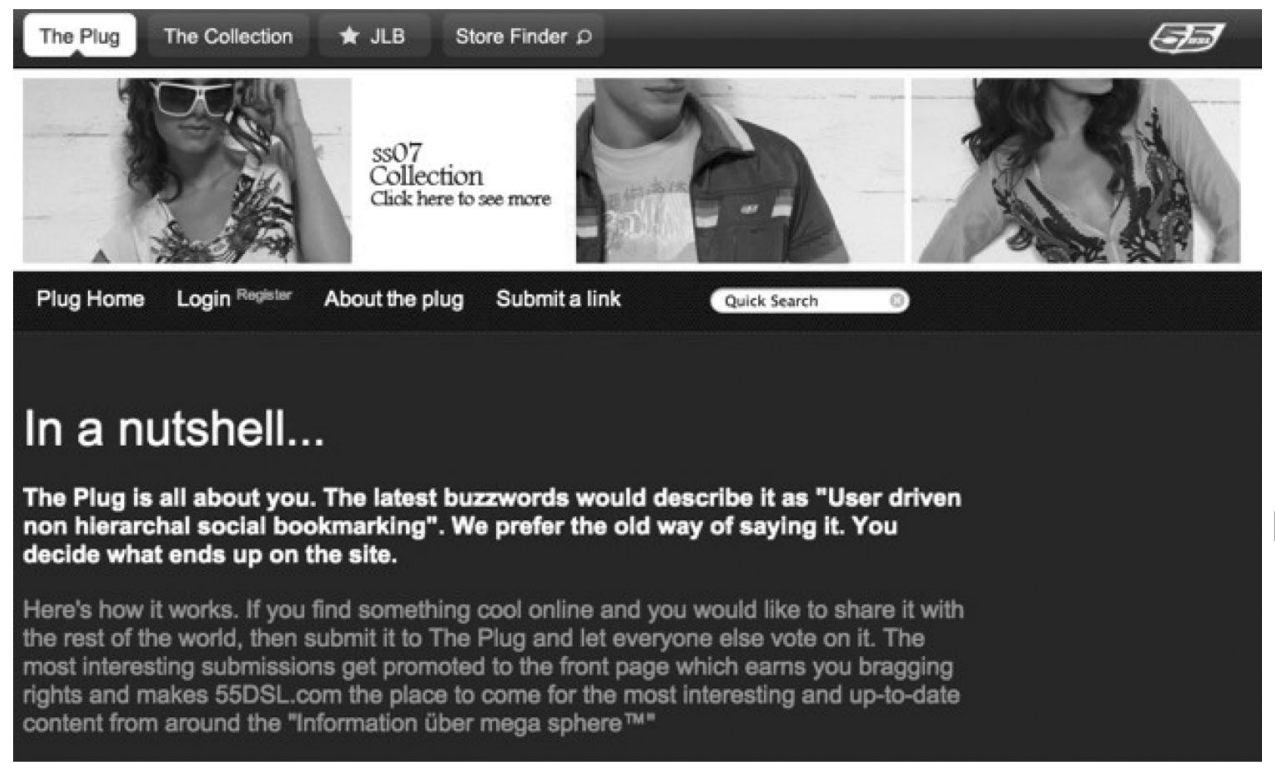

Figure 1. 55DSL website. Source: http://www.55dsl.com/?page=about 
attributed a prize-55DSL clothes specially designed in limited editions for the Need For Speed Carbon line. Winners of the weekly competitions participated in a draw competition that attributes other prizes, always from the same limited line. Creative consumers were called to design their outfits for the characters of the game, through a sort of design context that could bring innovative solutions and suggestions related to emerging preferences and styles among the company's consumers.

The philosophy of being a brand close to the most vivid trends in the most "fashionable" cities in the world gave life also to another online initiative, called Junior Lucky Bastards. Every year the company selects two young customers and sends them around the world in cities like Paris, Tokyo, Los Angeles and the like for 55 days. The two young reporters had to take pictures, movies and music from every place and maintained a blog and a podcast. Customers in the community, through blog comments and email, suggested places to visit and things to do, and hot spots in the cities the two were visiting. As for the previous activities, this initiative had two objectives: creating a branded experience and gathering impressions and first-hand rich accounts of newer styles and trends upon which consumers on the website can comment and contribute.

Music is another important driver of the relationship between the company and the most advanced communities of consumers. 55DSL organizes several sponsored parties and musical events which are anticipated and promoted online through its website and sponsors also the production of music compilations and records by famous Italian artists which are very well known in the street and urban-oriented communities. The flagship store of the company in London organizes weekly events and musical gatherings, which are held by famous deejays and broadcasted through the Internet and through podcasts.

The strategy has proved to be potentially successful in terms of insights and ideas for new collections and lines coming from the creativity of consumers although it is not yet clear how sustainable this strategy can prove in the long run. In fact, there is no clear indication that the users interacting online with the company are actual customers of 55DSL products. The risks associated with this uncertainty are clear: insights, suggestions and ideas emerging from these interactions could be misleading in the process of development of new collections, lines and designs.

\subsection{Communities of Consumers and Innovation in Sport System: The Case of Alpinestars}

Alpinestars is a world-renowned brand in the motorbike boot and equipment industry, located in the sport system district of Montebelluna (Veneto region). The company started as a small manufacturer of ski boots in 1964 and shifted its focus to motorcycling boots and equipment-gloves, suits, technical protection and safety items-during the 1970s, following the relevant growth in popularity and market size of motor sports. It is actually among the leading brands in professional circuits such as Formula 1, MotoGP, Nascar, and has also developed casual clothing lines strongly inspired by the world of motor sports and street culture.

The company experienced strong growth during the last 10 years. In particular, between 1997 and 2002 the company more than doubled its revenues, passing from 40 million euros to 80, and between 2002 and 2005 it kept growing, both in terms of sales (100 million in 2004, 120 million in 2005) and in the number of employees, which account to more than 200 globally. Started as a traditional small company located in a specialized industrial 
district, it grew to become a major player with a strong international presence-more than half of the total turnover is generated on international markets.

Alpinestars has answered to a market which is particularly demanding under the functional and ergonomic standpoint and at the same time has succeeded in re-defining the nature of its products differentiating its lines of boots and equipment through an increasing aesthetic and "fashion" content-forms, colors, shapes and styles. Motor sports have in fact become strongly connected to cultures of consumption, which are strong drivers of identity building and sense of belonging by practitioners and enthusiasts. They demand an increased expressive content of the products they use in addition to performance. Alpinestars-as well as other Italian companies in the industry such as Dainese and Ducati in motorbike production-have been able to sense these dynamics in their markets and developed strong brands, innovative product concepts and recognizable designs and aesthetics (Verona and Prandelli, 2006).

As far as the functional characteristics of its products are concerned, Alpinestars maintains strong connections with professional pilots and lead users in motor sportsendorsed pilots in major circuits-as a source for novel ideas and novel solutions for the improvement of its products. Not only professional riders but also biking enthusiasts willing to share their competences are important actors in Alpinestars' innovation processes.

Product innovation in such an industry depends heavily on the ability to deliver subtle but extremely effective solutions in two areas: safety and comfort. In order to develop such solutions, contact with the most advanced and sophisticated users is required. Sponsoring champions has a double utility in this case: creating brand awareness and cooperating with the most demanding customers. Within the process of new product development, designers and engineers work closely, in multidisciplinary teams, in order to guarantee the perfect fit between the functional and ergonomic concepts and proposals coming from designers and the technical solutions elaborated by engineers.

While professional riders represent a fundamental source of information for new solutions development, their requests and demands are not necessarily connected to the requests of the general market. The company perceived the need to interact also with bikers and riders whose main concerns are not only related to extreme performances such as MotoGP races but to several other factors such as stylistic and design improvements and developments.

In order to tap from a valuable source of ideas and suggestions regarding the biking culture, the company moved its R\&D and design facilities to Torrance (Los Angeles, California), in order to relate to sophisticated, although not professional, bikers. Torrance is the homeland for freestyle biking and motocross, and being close to local communities of riders provides a second fundamental point of observation in order to develop further solutions, observing riders in their practices and dialoguing with them. Besides the functional improvements deriving from such a relationship, the company benefited from the immersion and participation in the overall biking culture which allowed it to monitor the specific trends undergoing in biking and similar communities-extreme sports enthusiasts and skaters-and develop innovative stylistic and aesthetic solutions. These sports in fact have a strong lifestyle connotation: often their practitioners are characterized by specific ways of dressing and behaving, and by specific cultures and values.

Being immersed in the physical location where the most innovative and sophisticated consumers are allows the company to catch the latest aesthetic trends. The company's 
designers entertain constant relationships with bikers in the area and participate in motorcycling events as a means to take part in the shared experience space (Prahalad and Ramaswamy, 2003) within which users' experimentations with styles, fashions and designs are captured by the company and capitalized in the new product development pipeline. Alpinestars' strong connection to the most sophisticated user communities in the world helped its brand to be legitimized among those communities and become one of the favorites.

A second instrument used by the company to strengthen its relationship with user communities is the Internet. Alpinestars' website is conceived as a hub for information related to the world of motorcycling (Figure 2). Several pilots are interviewed periodically by the company which then inserts audio, video and text contributions to specified areas in the website. Video shooting of races and performances are continuously provided to the visitors of the website and Randy Mamola, a famous biker now turned TV commentator for the MotoGP, and Peter Wilson, another famous TV commentator of MotoGP races, have their columns in a specific area of the website and interact with consumers. Podcasts are regularly produced and distributed after every major motorcycling and motor sport event.

The company has developed a proactive strategy towards communities through its physical close contact with the California racing community and has adopted a different approach on the Internet. Though the website is not community oriented, since it does not offer specific areas dedicated to consumer interaction, the company has started to monitor major motorcycling blogs and websites in order to draw useful suggestions related to the wider cultural and aesthetic trends being developed in motor sports enthusiast communities around the world. Blogs and motorbiking websites, personal photographic albums and multimedia contributions of bikers documenting their experiences, the events they take part in and their consumption contexts are often important for the company in order to adjust its

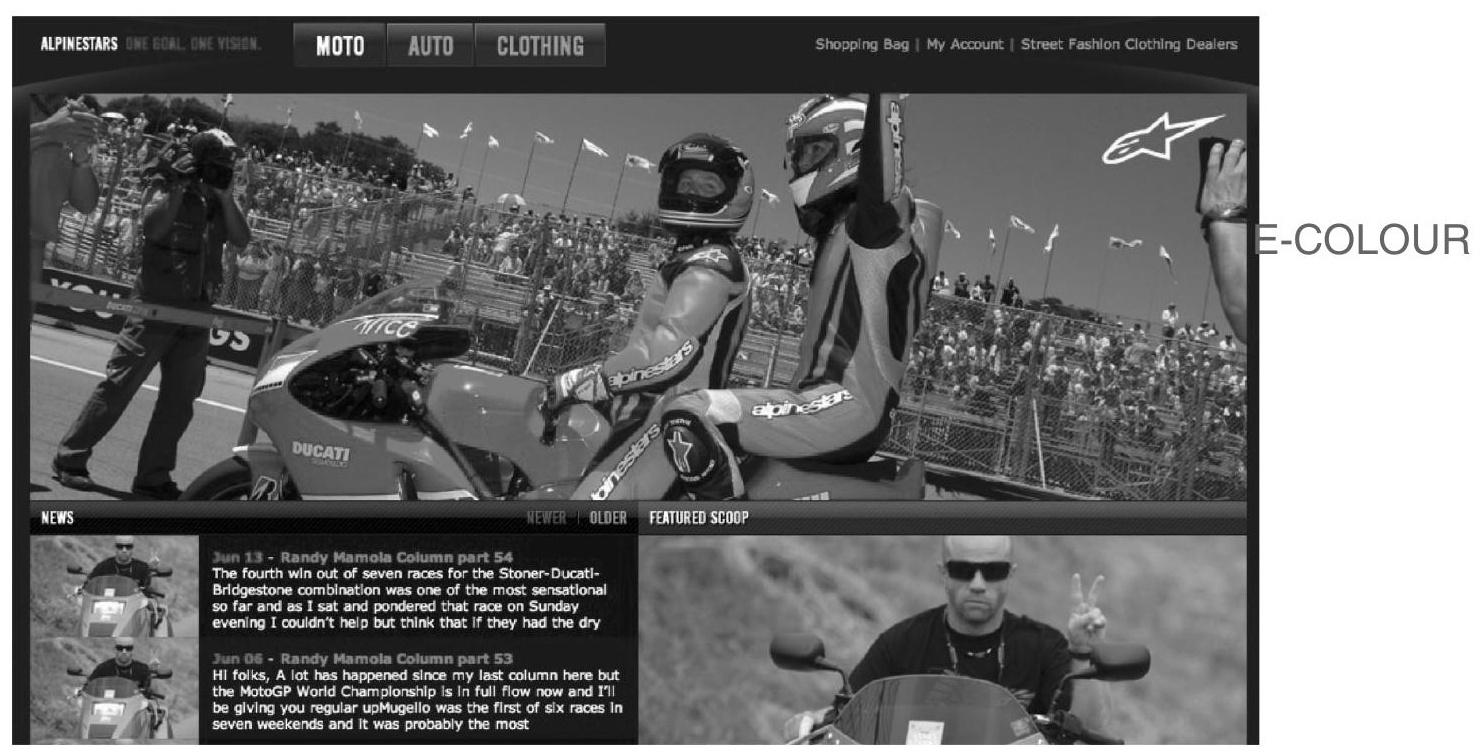

Figure 2. Alpinestars website. Source: http://alpinestarsinc.com/moto/mamola 
products' styles according to the trends emerging in consumer communities. Moreover, those insights are important to better understand the evolution of consumption cultures and consequently adapt Alpinestars' branding strategies and communication activities to maintain its legitimacy and credibility among riders and enthusiasts.

While in the case of 55DSL the company has opted for the construction of a branded space for its community-which is based on its websites and directly controlled by the firm-Alpinestars adopted a more open approach. Instead of hosting a specific community on its website, the company monitors the wider community of bikers and sports enthusiasts which is characterized by a strong identity and by a substantial loyalty towards several brands and products, as well as towards several interaction spaces-virtual and offline.

\section{Conclusions and Further Research Perspectives}

Our analysis on the role of consumer communities for Italian companies operating in lowtech industries unfolds promising research perspectives for further studies on the contributions of user communities in innovation processes. In particular, the consideration of user contributions to the intangible dimension of products suggests interesting integrations between theories in innovation studies and consumer studies as well as marketing in order to obtain a richer theoretical framework for the interpretation of the strategic role of consumer communities in innovation in markets for consumer goods.

The two case studies highlight insights companies can gain in terms of new ideas and feedbacks for product innovation and value creation, based on an explicit strategy of relationships with user communities. While the focus on manufacturing activities push many Italian SMEs to focus on industrial processes and, often, on functional characteristics of products, the attention to customers in their contexts of use and the understanding of social dynamics could support strategies of differentiation through the interplay of functional and intangible dimensions. In such a perspective, firms promote an intensive and interactive marketing approach, where the design of customer experiences as well as the messages and contexts proposed in their communication are built on the user's perspective, with their languages, values and sense-making results.

The role of ICT appears crucial to set up user-firm innovation circuits. Italian SMEs only recently started to recognize the potential of web technologies for the creation of rich relationships with customers. This means not only focusing on the firm's website, but also surfing the net and discovering customers' online environments, where valuable dynamics takes place.

As opposed to many other Italian SMEs specializing in medium and low-tech industries, 55DSL and Alpinestars have invested in a marketing strategy that explicitly puts lead users and communities at the core of their design and innovation processes. In addition, 55DSL has promoted an unconventional use of ICT in order to create and exploit the web as a customer management platform for experience sharing and brand interaction. Alpinestars refers to network technologies to share online experiences rooted in the physical context with customers, while monitoring existing independent communities for additional innovation inputs. Both the firms are SMEs where most of the manufacturing activities are outsourced to focus on value added processes such as product development and marketing, internally managed. 
Our empirical analysis is limited to two explorative case studies, from a managerial perspective it offers preliminary issues worth addressing with further studies. First, for a firm to rely on user communities requires structured and focused marketing strategies, where key elements are brands, communication and interaction. Second, firms have to develop novel competences and professional profiles, not exclusively product-oriented, but related also to marketing, technology and sociology. Third, firms have to upgrade their technology strategies, through a movement towards more mature models of ICT adoption and in particular towards the use of social and relational technologies (e.g. web 2.0 tools, see O'Reilly, 2005; Tapscott and Williams, 2006).

SMEs could benefit from these strategies, because of their vocational collaborative approach to markets (as in the case of the Made in Italy district model) as well as the economic advantages the communities and user-generated content approach can offer, compared to structured R\&D-based innovation. However, small size may become a limit in terms of competences and resource available internally-specifically in the domain of marketing or ICT—and require new forms of division of labor at the local and international level (networking as a solution to exploit external specialization).

A limitation of our study is that it is still preliminary and further analyses have to be carried out within the selected firms to explain how internal processes are changing. Moreover, an in-depth analysis should be promoted also at the community level, to understand the users' dynamics both in the virtual environment and offline. In addition, the set of incentives the firms have to develop should be further analyzed in order to obtain user's involvement into non-functional innovation processes. Future research should also focus on identifying measures able to evaluate how communities' impacts on innovation affect firm's performance. As many studies on communication and the role of intangible assets highlight, there are no systematic tools and procedures to quantify the returns of community management and their inputs on firm's economic results.

\section{Acknowledgements}

Marco Bettiol, Maria Chiarvesio, Stefano Micelli, the anonymous referees and the participants at the European Academy of Management conference held in Paris, 16-19 May 2007 whose comments have helped the improvement of this work are thanked. The shortcomings of the paper are the authors' responsibility alone.

\section{References}

Aaker, D. A. and Joachimsthaler, E. (2000) Brand Leadership (New York: Free Press).

Ahuvia, A. C. (2005) Beyond the extended self: loved objects and consumers' identity narratives, Journal of Consumer Research, 32, pp. 171-184.

Bagozzi, R. P. and Dholakia, U. M. (2006) Antecedents and purchase consequences of customer participation in small group brand communities, International Journal of Research in Marketing, 23, pp. 45-61.

Becattini, G. (1991) Italian industrial districts: problems and perspectives, International Studies of Management \& Organisation, 21, pp. 83-90.

Becattini, G. and Rullani, E. (1996) Local systems and global connections: the role of knowledge, in: F. Cossentino, F. Pyke \& W. Segenberger (Eds), Local and Regional Response to Global Pressure: The Case of Italy and its Industrial Districts (Geneva: International Institute for Labor Studies). 
Belk, R. W. (1988) Possessions and the extended self, Journal of Consumer Research, 15, pp. 139-168.

Belussi, F., Gottardi, G. and Rullani, E. (2003) The Technological Evolution of Industrial Districts (London: Kluwer).

Bettiol, M. and Micelli, S. (Eds) (2005) Design e creatività nel made in Italy. Proposte per i distretti industriali (Milano: Bruno Mondadori).

Chesbrough, H. W. (2003) Open Innovation (Cambridge, MA: Harvard Business School Press).

Chiarvesio, M., Di Maria, E. and Micelli, S. (2004) From local networks of SMEs to virtual districts? Evidence from recent trends in Italy, Research Policy, 33, pp. 1509-1528.

Corbellini, E. and Saviolo, S. (2004) La scommessa del Made in Italy e il futuro della moda italiana (Milano: Etas).

Corò, G. and Grandinetti, R. (1999) Evolutionary patterns of Italian industrial districts, Human Systems Management, 18, pp. 117-129.

Cova, B. (1997) Community and consumption: towards a definition of the "linking value" of products or services, European Journal of Marketing, 31, pp. 297-316.

Di Maria, E. and Micelli, S. (2007) Imprese del made in Italy, competitività e innovazione, in: G. Volpato (Ed.), I/ knowledge management come strumento competitivo. Un confronto intersettoriale (Roma: Carocci).

Economist, The (2007) Lessons from Apple. Available at http://www.economist.com/opinion/displaystory.cfm?story_id=9302662.

Franke, N. and Piller, F. (2004) Value creation by toolkits for user innovation and design: the case of the watch market, Journal of Product Innovation Management, 21, pp. 401-415.

Franke, N. and Shah, S. (2003) How communities support innovative activities: an exploration of assistance and sharing among endusers, Research Policy, 32(1), pp. 157-178.

Franke, N. and von Hippel, E. (2003) Satisfying heterogeneous user needs via innovation toolkits: the case of Apache security software, Research Policy, 32, pp. 157-178.

Hagel, J. and Armstrong, A. G. (1998) Net Gain: Expanding Markets through Virtual Communities (Boston: Harvard Business School Press).

Harhoff, D., Henkel, J. and von Hippel, E. (2003) Profiting from voluntary information spillovers: how users benefit by freely revealing their innovations, Research Policy, 32, pp. 1753-1769.

Hirschman, E. C. and Holbrook, M. B. (1982) Hedonic consumption: emerging concepts, methods and propositions, Journal of Marketing, 46, pp. 92-101.

Jenkins, H. (2006) Fans, Bloggers and Gamers. Exploring Participatory Culture (New York: New York University Press).

Jeppesen, L. B. and Fredriksen, L. (2006) Why firm-established user communities work for innovation? The personal attributes of innovative users in the case of computer-controlled music instruments, Organization Science, 17, pp. 45-64.

Jeppesen, L. B. and Molin, M. (2003) Consumers as co-developers: learning and innovation outside the firm, Technology Analysis and Strategic Management, 15, pp. 363-383.

Kotro, T. and Pantzar, M. (2002) Product development and changing cultural landscapes: is our future in snowboarding?, Design Issues, 18 , pp. $30-45$.

Kozinets, R. (1999) E-tribalized marketing? The strategic implications of virtual communities of consumption, European Management Journal, 17, pp. 252-264.

Krippendorf, K. and Butter, R. (1984) Product semantics: exploring the symbolic qualities of form in innovation, The Journal of the Industrial Designers Society of America, 3, pp. 4-9.

Lazerson, M. and Lorenzoni, G. (1999) The firms that feed industrial districts: a return to the Italian source, Industrial and Corporate Change, 8, pp. 235-266.

Leonard, D. and Rayport, J. F. (2000) Spark innovation through empathic design, Harvard Business Review, 6, pp. $103-115$.

Lush, R. F., Vargo, S. L. and O'Brien, M. (2007) Competing through service: insights from service-dominant logic, Journal of Retailing, 83(1), pp. 5-18.

Maffesoli, M. (1992) La trasfiguration du politique: la tribalization du monde (Paris: Grasset).

Micelli, S. (2000) Imprese, reti e comunità virtuali (Milano: Etas).

Morling, M. S. and Strannegard, L. (2004) The silence of the brands, European Journal of Marketing, 38, pp. 224-238.

Morrison, P. D., Midgley, D. F. and Roberts, J. H. (2004) The nature of lead users and measurement of leading edge status, Research Policy, 33, pp. 351-362.

Muniz, A. M. and O'Guinn, T. (2001) Brand community, Journal of Consumer Research, 27, pp. 412-432.

Nambisan, S. (2002) Designing virtual customer environments for new product development: towards a theory, Academy of Management Review, 27, pp. 392-413.

Normann, R. (2001) Reframing Business: When the Map Changes the Landscape (Chichester: Wiley). 
Nussbaum, B., Berner, R. and Brady, D. (2005) Get creative!, Business Week, Issue 3945, pp. 60-68.

O'Reilly, T. (2005) What is web 2.0? Design patterns and business models for the next generation of software, O'Reilly Net. Available at http://www.oreillynet.com.

Pine, B. J. and Gilmore, J. (1999) The Experience Economy (Boston: Harvard Business School Press).

Pine, B. J. and Gilmore, J. (2007) Authenticity. What Consumers Really Want (Boston: Harvard Business School Press).

Porter, M. E. (1985) The Competitive Advantage: Creating and Sustaining Superior Performance (New York: Free Press).

Postrel, V. (2004) The Essence of Style (New York: HarperCollins).

Prahalad, C. K. and Ramaswamy, V. (2003) The new frontier of experience innovation, MIT Sloan Management Review, 44, pp. 12-18.

Pyke, F., Becattini, G. and Segenberger, W. (Eds) (1990) Industrial Districts and Inter-firm Cooperation in Italy (Geneva: International Institute for Labour Studies).

Ravasi, D. and Lojacono, G. (2005) Managing design and designers for strategic renewal, Long Range Planning, 38, pp. 51-77.

Rémy, E. and Kopel, S. (2002) Social linking and human resource management in the service sector, The Service Industries Journal, 22(1), pp. 35-56.

Rheingold, H. (2002) Smart Mobs (Cambridge: Perseus).

Roberts, K. (2004) Lovemarks: The Future Beyond Brands (New York: PowerHouse Books).

Rosenberg, N. (1982) Inside the Black Box: Technology and Economics (Cambridge: Cambridge University Press).

Rullani, E. (2004) La fabbrica dell'immateriale (Roma: Carocci).

Sawhney, M. and Prandelli, E. (2000) Communities of creation: managing distributed innovation in turbulent markets, California Management Review, 42, pp. 24-54.

Schmitt, B. and Simonson, A. (1997) Marketing Aesthetics. The Strategic Management of Brands, Identity and Management (New York: Free Press).

Schouten, J. W. and McAlexander, J. H. (1995) Subcultures of consumption: an ethnography of new bikers, Journal of Consumer Research, 22, pp. 43-61.

Siggelkow, N. (2007) Persuasion with case studies, Academy of Management Journal, 50, pp. $20-24$.

Silverstein, J. M. and Fiske, N. (2003) Trading Up. The New American Luxury (New York: Portfolio).

Sproull, L. and Kiesler, S. (1991) Connections. New Ways of Working in the Networked Organization (Cambridge, MA: MIT Press).

Tapscott, D. and Williams, A. D. (2006) Wikinomics. How Mass Collaboration Changes Everything (New York: Portfolio).

Verganti, R. (2006) Innovation through design, Harvard Business Review, 84, pp. 114-122.

Verona, G. and Prandelli, E. (2006) Collaborative innovation. Marketing e organizzazione per i nuovi prodotti (Roma: Carocci).

Veryzer, R. V. (2005) The role of marketing and industrial design in discontinuous new product development, Journal of Product Innovation Management, 22, pp. 22-41.

von Hippel, E. (1988) The Sources of Innovation (New York: Oxford University Press).

von Hippel, E. (1994) Sticky information and the locus of problem solving: implications for innovation, Management Science, 40, pp. 429-439.

von Hippel, E. (2001) Innovation by user communities: learning from open source software, MIT Sloan Management Review, 42, pp. 82-86.

von Hippel, E. (2005) Democratizing Innovation (Boston: MIT Press).

von Hippel, E. and von Krogh, G. (2003) Open source software and the private-collective model of innovation: issues for organization science, Organization Science, 14, pp. 208-223.

Yin, R. K. (1994) Case Study Research: Design and Methods (Thousand Oaks, CA: Sage). 